\title{
A Kinetic Study of Candida rugosa Lipase-Catalyzed Synthesis of 4,6-Dimethyl-3-cyano-2-pyridone
}

\author{
Nevena Ž. Prlainović, Dejan I. Bezbradica, Zorica D. Knežević-Jugović, \\ Roksana T. Kozlowska and Dušan Ž. Mijin*
}

Faculty of Technology and Metallurgy, Karnegijeva 4, P.O. Box 3503, 11120 Belgrade, Serbia

\begin{abstract}
A síntese da 4,6-dimetil-3-ciano-2-piridona foi estudada na reação catalisada pela lipase de Candida rugosa. A metodologia de superfície de resposta (MSR) foi aplicada para a otimização das condições experimentais. O estudo mostrou que a temperatura e a razão molar cianoacetamida/ acetilacetona têm grande influência sobre o rendimento da reação. O rendimento máximo foi obtido a $44^{\circ} \mathrm{C}$ e razão molar cianoacetamida/acetilacetona igual a 36. A cinética da síntese enzimática da 4,6-dimetil-3-ciano-2-piridona foi investigada, e foi determinado que o mecanismo ping-pong bi-ter com inibição da cianoacetamida é coerente com os resultados obtidos. O mecanismo da reação catalisada pela Lipase foi proposto.
\end{abstract}

The synthesis of 4,6-dimethyl-3-cyano-2-pyridone was studied in a reaction catalyzed with Candida rugosa lipase. A response surface methodology (RSM) was applied for the optimization of the experimental conditions. The study showed that temperature and molar ratio cyanoacetamide/ acetylacetone have a great influence on the yield of the reaction; the maximum yield was achieved at $44{ }^{\circ} \mathrm{C}$ with a molar ratio cyanoacetamide/acetylacetone of 36 . The kinetics of the enzymatic synthesis of 4,6-dimethyl-3-cyano-2-pyridone was investigated, and it was determined that a pingpong bi-ter mechanism with cyanoacetamide inhibition fits the obtained results. The mechanism of lipase-catalyzed reaction was proposed.

Keywords: Candida rugosa lipase, ping-pong kinetics, cyanoacetamide inhibition, acetylacetone, pyridone

\section{Introduction}

Substituted 3-cyano-2-pyridones are important intermediates in the pharmaceutical, dye and photo industries, and they are also used as fuel and oil additives. ${ }^{1}$ In addition, 4,6-disubstituted-3-cyano-2-pyridones are used as active components of drugs that increase cardiac contractility. ${ }^{2-4}$ Their syntheses have been widely studied using conventional heating in the presence of various catalysts and they were usually performed in polar solvents. ${ }^{1,5}$ In the study of condensation of various 1,3-diketones with cyanoacetamide, different strategies have been used, including phase-transfer catalysis and enzymatic catalysis. ${ }^{5}$

Lipases, also known as triacylglycerol ester hydrolases, are enzymes that cleave ester bonds of triacylglycerols with the subsequent release of free fatty acids, diacylglycerols, monoacylglycerols and glycerol. Lipases are also

*e-mail: kavur@tmf.bg.ac.rs able to catalyze the reverse reactions (esterification, interesterification and transesterification), provided that the aqueous medium is replaced by an organic or a biphasic aqueous/organic medium. ${ }^{6,7}$ Lipases also show high regio- and stereo-selectivity and give products of high purity and improved quality. ${ }^{8-11}$ This is a very important property in the pharmaceutical industry, because only one enantiomer shows pharmacological activity. Lipases can be used for the resolution of racemic mixures, ${ }^{12-15}$ and for the enantioselective preparation of intermediates in the synthesis of a large number of chiral drugs and drug intermediates. ${ }^{16,17}$ For example, lipase from Aspergillus niger is used for the resolution $(R, S)$-ibuprofen enantiomers ${ }^{18}$ the synthesis of optically pure Citalopram is mediated by an enantioselective reaction catalyzed by lipase from Candida antartica. ${ }^{19}$

Lipases, including Candida rugosa, formerly $C$. cylindracea, were used to synthesize the substituted 3-cyano-2-pyridones (Figure 1). ${ }^{20-23}$ Unlike conventional syntheses that require heating in the presence of various 
catalysts and usually polar organic solvents, enzymatic synthesis was achieved under mild reaction conditions. Under such conditions, various 4,6-disubstituted-3-cyano2-pyridones were obtained, including aryl-substituted 3-cyano-2-pyridones. It was shown that when an unsymmetrical diketone was used, different ratios of products were obtained in the chemical and enzymatic reaction. ${ }^{21}$ Due to the high selectivity of lipases, practically only one, of two possible isomers, were obtained. ${ }^{20,21}$ In addition, the influence of $\mathrm{N}$-substituted cyanoacetamides and 3-substituted acetylacetones on the enzymatic synthesis of 4,6-disubstituted-3-cyano-2-pyridones was studied and it was found that the introduction of alkyl groups into the molecule of acetylacetone had a greater impact on the reaction in comparison to the corresponding substituted cyanoacetamides. ${ }^{23}$

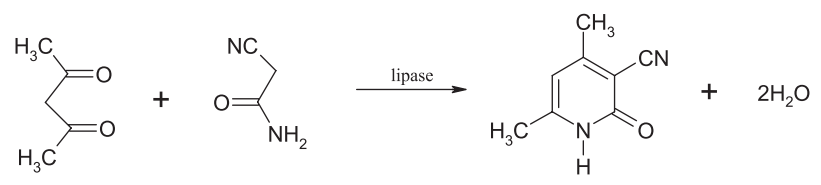

Figure 1. Synthesis of 4,6-dimethyl-3-cyano-2-pyridone from acetylacetone and cyanoacetamide catalyzed by lipase.

The results of previous investigations indicated that the yield of lipase-catalyzed syntheses of substituted 3-cyano-2-pyridones are influenced by various factors, such as reaction temperature, type of substrate, substrate molar ratio and enzyme concentration. ${ }^{20-23}$ An investigation of the impact of various 1,3-diketones on the pyridone synthesis showed that increasing the number of carbon atoms in diketone molecule decreased the yield and the initial reaction rate. ${ }^{22}$ For these reasons, all the experiments in this work were performed with the simplest 1,3-diketone (2,4-pentanedione). The influence of three reaction factors (temperature, substrate molar ratio and enzyme concentration) on the synthesis of 4,6-dimethyl-3-cyano-2pyridone was investigated using central composite rotatable design (CCRD) and the response surface methodology (RSM). Application of CCRD significantly reduces the number of experiments required for optimization and RSM is a method that combines mathematics and statistics in order to analyze the relationships between several variables and one or more response variable, and enables the quantification of the individual effect of each factor. ${ }^{24}$

The kinetics of this reaction was previously studied using Henry-Michaelis-Menten and allosteric enzyme kinetics models, ${ }^{22}$ but these models cannot adequately describe complex enzymatic reactions that involve two substrates. Therefore, in this work, in order to obtain a deeper insight into the kinetics and to elucidate the mechanism of the studied reaction, the dependence between the initial rate of reaction and the concentrations of the substrates was analyzed and two kinetic models were used for fitting the results, i.e., the ordered bi-ter and ping-pong bi-ter model. The kinetic study was performed at optimal values of the reaction temperature and enzyme concentration, previously determined by RSM methodology.

\section{Experimental}

\section{Reagents}

Candida rugosa lipase (EC 3.1.1.3), Type VII, activity 1410 units $\mathrm{mg}^{-1}$ of solid was purchased from the Sigma Chemical Co. (St. Louis, USA). The substrates, 2,4-pentadione and cyanoacetamide were purchased from Fluka (Buchs, Switzerland).

\section{Methods}

Synthesis of 4,6-dimethyl-3-cyano-2-pyridone was performed in $100 \mathrm{~mL}$ flasks. Cyanoacetamide, acetylacetone and the enzyme were added based on the experimental plan. Subsequently, the reaction mixtures were diluted with $10 \mathrm{~mL}$ of water and the flasks were placed on a shaker at $150 \mathrm{rpm}$, at the required temperature. After certain period $(0.5,1,2,3$ and $24 \mathrm{~h}), 0.2 \mathrm{~mL}$ of liquid was taken from the system, diluted with water to $25 \mathrm{~mL}$ and analyzed by UV spectrophotometry (UV Shimadzu 1700, Shimadzu Corporation, Kyoto, Japan) at $320 \mathrm{~nm}$ (maximum absorption of 4,6-dimethyl-3-cyano-2-pyridone). The concentration of the product was calculated employing data of a standard curve obtained using 4,6-dimethyl-3-cyano2-pyridone. Control tests, under the same conditions but without enzyme, were also run for each sample. All the results given in the kinetic studies and RSM optimization represent the difference between yields of the reactions in the presence of the lipase and the control tests. The initial reaction rates were obtained from the experimental concentration-time profiles by linear regression of the data over the first $3 \mathrm{~h}$.

\section{Experimental design and data analysis}

The response surface methodology was used to study the simultaneous effect of temperature, enzyme concentration and cyanoacetamide/acetylacetone molar ratio on the yield of 4,6-dimethyl-3-cyano-2-pyridone. The optimization was based on a five-level-three-factor central composite rotatable design, which consisted of fourteen experimental runs including six replicates at the center 
point. The design contained three major components. The first was an embedded factorial with two levels of each of the factors, coded as -1 and +1 . The second component of the design was the star points. There had to be sufficient of these to allow an estimation of the curvature of the model and preferably be chosen so that the standard error of the response variable was the same at any point of the fitted surface. This was achieved by selecting six points equally spaced around the circumference of a circle with a radius equal to \pm 1.682 . As the factorial and star experimental combinations were not replicated, a number of centre points were added as the third component in order to provide degrees of freedom for estimating the experimental error and also to determine the precision of the response variable near to the centre. The number of the centre points was chosen so that the standard error of the estimate of the response variable was approximately the same at the centre as at all points in the circle with radius $1 .{ }^{25}$

The temperature was varied between 23.6 and $56.8^{\circ} \mathrm{C}$, enzyme concentration between 0.074 and $0.326 \%(\mathrm{~m} / \mathrm{v})$ and the cyanoacetamide/acetylacetone molar ratio between 9.8 and 60.2. All design points, except the central one, were done in duplicate. The obtained data were fitted to a second-order polynomial equation:

$Y=b_{o}-\sum_{i=1}^{3} b_{i} X_{i}-\sum_{i=1}^{3} b_{i i} X_{i}^{2}-\sum_{i=1}^{3} b_{i j} X_{i} X_{j}$

where $Y$ is the response variable, $b_{0}, b_{\mathrm{i}}, b_{\mathrm{ii}}$ and $b_{\mathrm{ij}}$ are the intercept, linear, quadratic and interaction coefficients, respectively, and $X_{\mathrm{i}}$ and $X_{\mathrm{j}}$ are independent variables. The yield of 4,6-dimethyl-3-cyano-2-pyridone was taken as the dependent variable $(Y)$ of the response.

The coefficients of the response function and their statistical significance were evaluated by the least squares method using MATLAB software (version 6.5, Release 13, The MathWorks, Juc, Matick, MA, USA). Only the significant terms $(p \leq 0.05)$ were considered for the final reduced model. The Fisher test was used to determine model adequacy and the Student distribution to evaluate the significance of the coefficients.

\section{Results and Discussions}

In a preliminary experiment, the synthesis of 4,6-dimethyl-3-cyano-2-pyridone was performed at $40{ }^{\circ} \mathrm{C}$ and with considerable molar excess of cyanoacetamide $(10: 1)$ and with $0.2 \%(\mathrm{~m} / \mathrm{v})$ of enzyme. Simultaneously, a control experiment was performed without the enzyme but otherwise under the same conditions in order to estimate the contribution of lipase in comparison to the spontaneous chemical reaction. The obtained results (illustrated in Figure 2) undoubtedly confirmed the catalytic role of the lipase, since in the reaction with lipase significantly higher initial rates of reaction were achieved. After $24 \mathrm{~h}$, the product yield in the lipase-catalyzed reaction was almost $45 \%$, while the yield in the spontaneous chemical reaction was less than $5 \%$.

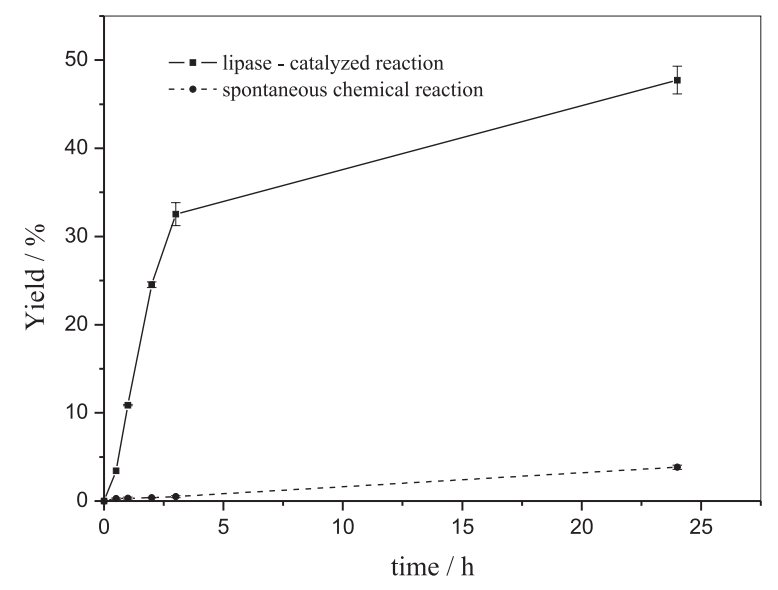

Figure 2. Yield of 4,6-dimethyl-3-cyano-2-pyridone at $40{ }^{\circ} \mathrm{C}$, with a substrate molar ratio 10 .

\section{Model fitting and statistical analysis}

In order to attain even higher reaction rates and yields and utilize the maximum catalytic potential of lipase, optimization of the experimental factors was performed using the response surface methodology. This methodology is an optimization technique and it was used for the assessment of the impact of factors previously stressed as the most important in the synthesis of 4,6-dimethyl3-cyano-2-pyridone: temperature, lipase concentration and substrate molar ratio. The central composite rotatable design, with codified levels and real values of the independent variables presented in Table 1, was conducted in order to determine the influence each factor exerts on the yield of 4,6-dimethyl-3-cyano-2-pyridone and, moreover, to investigate the interactions between these factors. The overall three-factor-five-level central composite experimental design and experimental data are shown in Table 2. The results listed in the last column of Table 2 represent the contribution of the enzymatic reaction to the overall yield. They were calculated by subtraction of the yield of the spontaneous chemical reaction (without enzyme) from the yield of the reaction in the presence of the enzyme. The yields of 4,6-dimethyl-3-cyano-2pyridone varied between 37.66 and $73.14 \%$. The highest molar conversion $(73.14 \%)$ was achieved in run No. 2 (temperature $50{ }^{\circ} \mathrm{C}$, enzyme concentration $0.125 \%$, and 
substrate ratio 20), while the smallest molar conversion $(37.66 \%)$ was achieved in run No. 9 (temperature $23.2^{\circ} \mathrm{C}$, enzyme concentration $0.2 \%$, and substrate ratio 35 ). It can be seen that the application of the proper experimental design led to a significant increase in the product yield (in comparison to the preliminary experiment) after a relatively small number of performed experiments.

Table 1. Independent variables and their coded levels used for the optimization

\begin{tabular}{lccccc}
\hline Variables & \multicolumn{5}{c}{ Coded levels of the variables } \\
& -1.682 & -1 & 0 & 1 & 1.682 \\
\hline Temperature, $X_{1} /{ }^{\circ} \mathrm{C}$ & 23.2 & 30 & 40 & 50 & 56.8 \\
Enzyme concentration, & 0.074 & 0.125 & 0.2 & 0.275 & 0.326 \\
$X_{2} / \%(\mathrm{~m} / \mathrm{v})$ & & & & & \\
Substrate molar ratio, $X_{3}$ & 9.8 & 20 & 35 & 50 & 60.2 \\
\hline
\end{tabular}

Table 2. The response surface central composite design and the experimental data

\begin{tabular}{|c|c|c|c|c|}
\hline $\begin{array}{l}\text { Run } \\
\text { No. }\end{array}$ & $\begin{array}{c}\text { Temperature, } \\
X_{1} /{ }^{\circ} \mathrm{C} \\
\end{array}$ & $\begin{array}{c}\text { Enzyme concen- } \\
\text { tration, } X_{2} / \%\end{array}$ & $\begin{array}{c}\text { Substrate molar } \\
\text { ratio, } X_{3}\end{array}$ & $\begin{array}{c}\text { Experimental } \\
\text { Data }^{\mathrm{b}}\end{array}$ \\
\hline 1 & -1 & -1 & -1 & $41.51( \pm 0.08)$ \\
\hline 2 & 1 & -1 & -1 & $73.14( \pm 1.57)$ \\
\hline 3 & -1 & 1 & -1 & $41.51( \pm 0.47)$ \\
\hline 4 & 1 & 1 & -1 & $70.81( \pm 0.08)$ \\
\hline 5 & -1 & -1 & 1 & $60.82( \pm 2.20)$ \\
\hline 6 & 1 & -1 & 1 & $68.60( \pm 0.71)$ \\
\hline 7 & -1 & 1 & 1 & $59.32( \pm 2.34)$ \\
\hline 8 & 1 & 1 & 1 & $69.60( \pm 1.57)$ \\
\hline 9 & -1.682 & 0 & 0 & $37.66( \pm 0.43)$ \\
\hline 10 & 1.682 & 0 & 0 & $43.41( \pm 2.09)$ \\
\hline 11 & 0 & -1.682 & 0 & $69.42( \pm 0.78)$ \\
\hline 12 & 0 & 1.682 & 0 & $70.81( \pm 0.98)$ \\
\hline $13^{\mathrm{a}}$ & 0 & 0 & 0 & $72.14( \pm 3.22)$ \\
\hline 14 & 0 & 0 & -1.682 & $43.89( \pm 1.29)$ \\
\hline 15 & 0 & 0 & 1.682 & $42.78( \pm 1.84)$ \\
\hline
\end{tabular}

${ }^{\mathrm{a}}$ Center point (6 replicates). ${ }^{\mathrm{b}}$ Average values.

After performing the Fisher test, it was concluded that the second-order model is adequate for describing this set of experimental results. Subsequently, the Student test was applied to evaluate the significance of the coefficients. Only the significant terms $(p \leq 0.05)$ were considered for the final reduced model. After elimination of the insignificant coefficients, the statistical model described by the following equation was obtained:

$Y=70.18+6.45 X_{1}-9.09 X_{1}^{2}-5.36 X_{1} X_{3}-7.33 X_{3}^{2}$
It was found that the lipase concentration in the applied concentration range $(0.074-0.326 \% \mathrm{~m} / \mathrm{v})$ and this significance level was not a significant factor in the synthesis of 4,6-dimethyl-3-cyano-2-pyridone. It was established that two parameters were significant: temperature $\left(X_{1}\right)$ and substrate molar ratio $\left(X_{3}\right)$. Both, the linear and quadratic coefficients of each factor were significant, as well as the term describing their correlation. The three-dimensional surface representing the yield of pyridone versus temperature and substrate molar ratio is presented in Figure 3a, and the contour plot is presented in Figure $3 b$. It is obvious that both factors strongly influence the enzymatic reaction; hence, it is plausible that the effect of the lipase concentration was statistically undetectable due to the very intensive effects of the other factors.

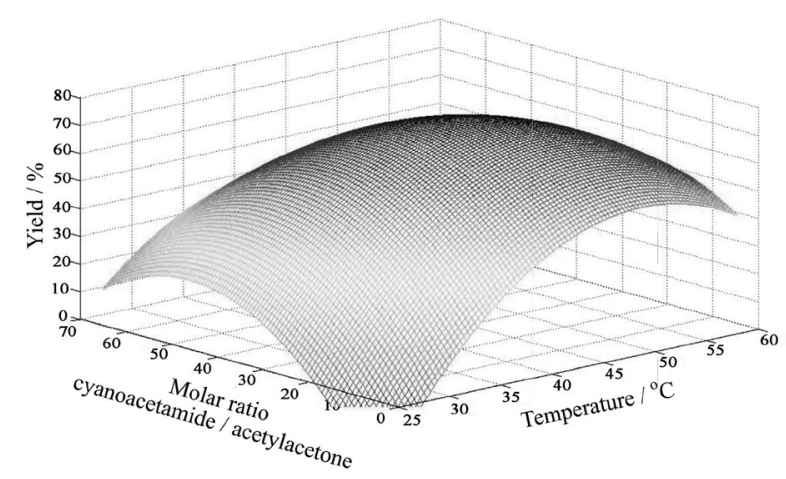

Figure 3a. Three-dimensional surface representing the yield of pyridone versus temperature and substrate molar ratio.

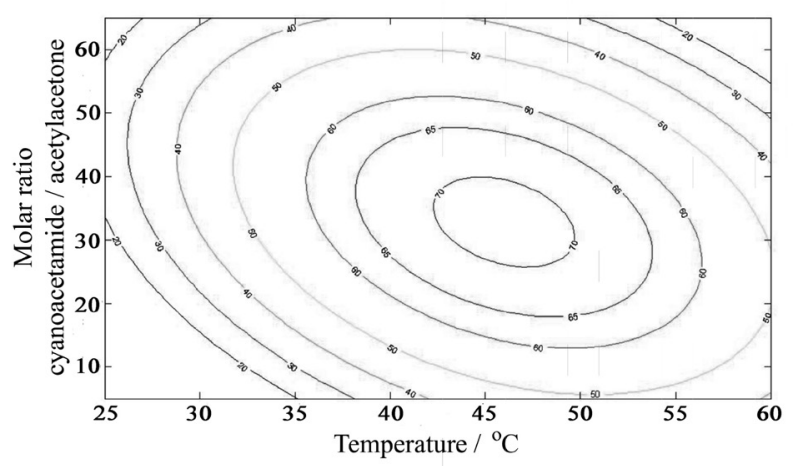

Figure 3b. Contour plot for the yield of pyridone as a function of temperature and substrate molar ratio.

The quadratic coefficients were negative, hence both factors have characteristic values where the dependent variable exhibits a maximum value. Thus, it appears that the yield of 4,6-dimethyl-3-cyano-2-pyridone increased until the temperature reached the optimal value, after which the yield decreases, probably due to thermal denaturation of the enzyme. The same tendency was observed in the analysis 
of the influence of the substrate ratio, since increasing the excess of cyanoacetamide to 36-fold resulted in an increase in the product yield. It is plausible that a significant excess of cyanoacetamide is required for the formation of a sufficient quantity of enzyme-substrate complex, which was emphasized as a prerequisite for reactions catalyzed with lipase from C. rugosa..$^{26,27}$ The decrease in the yield with further increase of the cyanoacetamide/acetylacetone ratio is probably caused by inhibition with so high an excess of cyanoacetamide or such a high concentration of cyanoacetamide can create diffusion obstacles in the enzyme microenvironment for the approach of the second substrate. The obtained model indicated that the maximum yield of 4,6-dimethyl-3-cyano-2-pyridone could be expected in a reaction performed at $44{ }^{\circ} \mathrm{C}$ with a cyanoacetamide/acetylacetone ratio of 36 .

In addition, the activation energy was calculated from an Arrhenius plot. ${ }^{28}$ During the initial period, the effect of temperature on the synthesis of the pyridone followed the Arrhenius law, with an activation energy of $71.98 \mathrm{~kJ} \mathrm{~mol}^{-1}$.

\section{Kinetics and mechanism of the non-enzymatic reaction}

The mechanism of the cyclocondensation of cyanoacetamide with acetylacetone and a catalytic amount of a base is presented in Scheme 1. This kind of catalytic process is broadly described as carboanion addition to a carbonyl function, which includes many reactions such as Claisen, Michael and Perkin condensation. Since the cyanoacetamide is a weak acid, there is an initial fast equilibrium between cyanoacetamide and basic catalysts, yielding the carboanion nucleophile (I). Acetyalacetone is enolised and subject to self condensation, which leads to a highly complex kinetic behavior. The next step, attack of the nucleophile at the delocalized acetylacetone (II) is the rate determining step. The subsequent protonation-dehydration (III) and cyclization step (IV) are probably fast equilibria and the last step (V), dehydration, yields the stable delocalized pyridine structure, which is undoubtedly irreversible. ${ }^{1}$

\section{Enzymatic kinetics mechanism}

Previous studies of the kinetics of the enzyme-catalyzed synthesis of 4,6-disubstituted-3-cyano-2-pyridones showed that the behavior of the lipase used as the catalyst in the synthesis of 4,6-dimethyl-3-cyano-2-pyridone is more complicated than that of chemical catalysts. ${ }^{22}$

In order to determine the kinetic model of this reaction and the kinetic constants, a series of kinetic experiments were performed using various pairs of concentrations of acetylacetone and cyanoacetamide and the initial reaction rates, at the optimal temperature of $44{ }^{\circ} \mathrm{C}$ and enzyme concentration of $4 \times 10^{-3} \mathrm{mg} \mathrm{mL}^{-1}$, were determined. The acetylacetone concentration was varied in the range $2 \times 10^{-5}-12 \times 10^{-5} \mathrm{~mol} \mathrm{~mL}^{-1}$, while the cyanoacetamide concentration was between $1.2 \times 10^{-3}$ and $6 \times 10^{-3} \mathrm{~mol} \mathrm{~mL}^{-1}$. Higher cyanoacetamide concentrations were applied because an excess of cyanoacetamide is necessary to achieve high initial rates and high yields of the product, ${ }^{20-23}$ as was shown in the previous section. The obtained results are illustrated in Figure 4.<smiles>CC(C)C=C(C#N)C(N)=O</smiles>

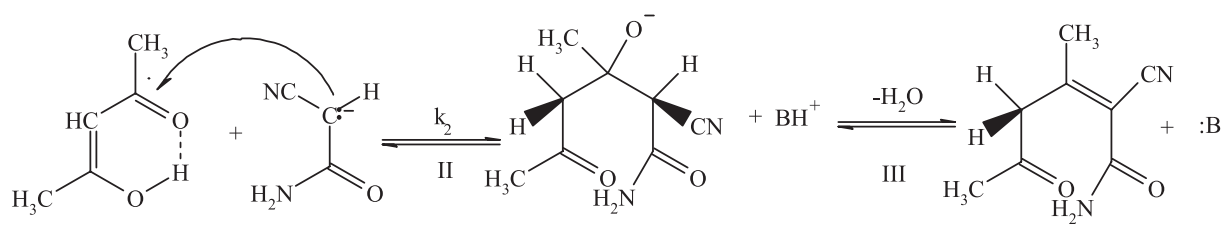
IV<smiles>Cc1cc(C)c(C#N)c(O)n1</smiles><smiles>CC1=C(C#N)C(=O)N[C@H](O)[C@H]1C</smiles>

Scheme 1. Mechanism of the condensation of acetylacetone with cyanoacetamide yielding 4,6-dimethyl-3-cyano-2-pyridone in the chemically catalyzed reaction. 


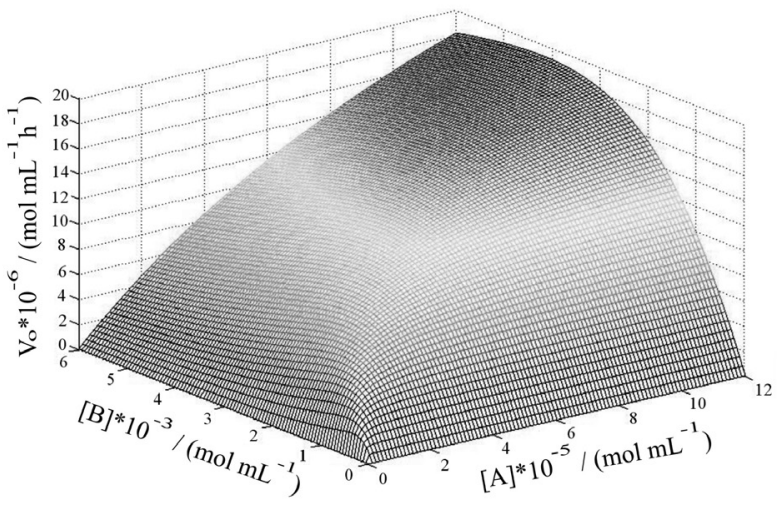

Figure 4. Illustration of the proposed ping-pong bi-ter model.

It seems that increasing the acetylacetone concentration until aproximately $10^{-4} \mathrm{~mol} \mathrm{~mL}^{-1}$ leads to a rapid increase in the initial rates of the reaction, with subsequently a slow approach to local maximum values. Therefore, the effect of this substrate was in accordance with MichaelisMenten kinetics, which was further confirmed by the linear dependence obtained in Lineweaver-Burke plot of the initial rates $\left(V_{\mathrm{o}}^{-1}\right)$ versus substrate concentration (Figure 5). On the other hand, increasing the concentration of cyanoacetamide up to approximately $3.6 \times 10^{-3} \mathrm{~mol}$ $\mathrm{mL}^{-1}$ also led to an increase of initial rates, but a further increase of cyanoacetamide concentration led to a rapid decrease in the rates (Figure 4). Such a behavior implies inhibition of $C$. rugosa lipase by cyanoacetamide in this reaction. The non-linear appearance of the experimental data in the Lineweaver-Burke plot is further corroboration of this hypothesis (Figure 6). The maximum initial rate of $124 \mu \mathrm{mol} \mathrm{mL} \mathrm{mL}^{-1} \mathrm{~h}^{-1}$ was achieved at $12 \times 10^{-5} \mathrm{~mol} \mathrm{~mL}^{-1}$ of acetylacetone and $3.6 \times 10^{-3} \mathrm{~mol} \mathrm{~mL}^{-1}$ of cyanoacetamide.

After preliminary analysis of the results, two kinetic models were tested: the ping-pong model with inhibition by one substrate and an ordered model with inhibition by one substrate. ${ }^{29,30}$ After statistical analysis, it was noticed that the correlation between the ordered model (with cyanoacetamide inhibition) and the experimental results was very poor, with a correlation coefficient lower than 0.8 . On the other hand, the ping-pong model, which included inhibition by cyanoacetamide, was in good agreement with the obtained results, with a correlation coefficient of 0.958 . Since the water concentration was constant during the reaction, the ping-pong bi-ter model including substrate inhibition can be described by the following equation: ${ }^{26,31}$

$$
v=\frac{V_{\max }[A][B]}{K_{m}^{B}[A]+\alpha \mathrm{K}_{\mathrm{m}}^{\mathrm{A}}[B]\left(1+\frac{[B]}{K_{i, B}}\right)+[A][B]}
$$

where $v$ is the initial reaction rate, $V_{\max }$ is the maximum reaction rate, $[\mathrm{A}]$ and $K_{\mathrm{m}, \mathrm{A}}$ are the concentration and Michaelis constant for acetylacetone, [B] and $K_{\mathrm{m}, \mathrm{B}}$ are the concentration and Michaelis constant for cyanoacetamide, respectively, and $K_{\mathrm{i}, \mathrm{B}}$ is the inhibition constant for cyanoacetamide.

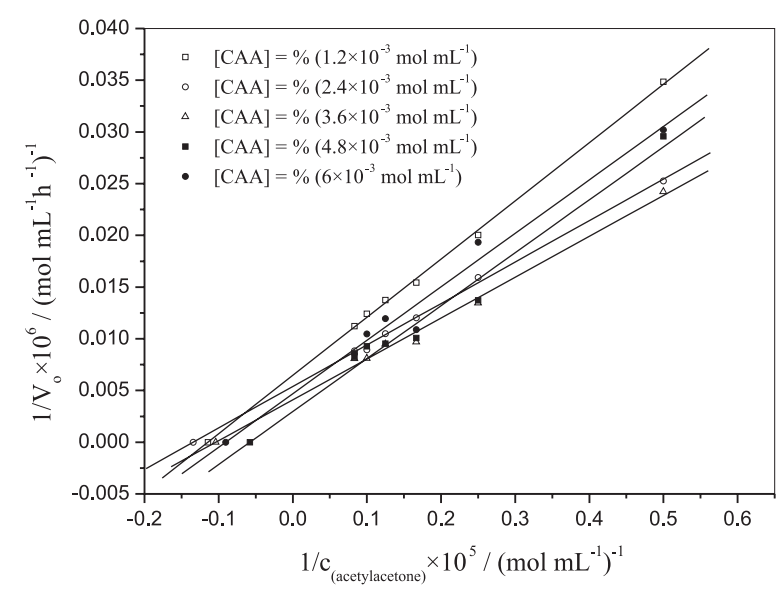

Figure 5. Reciprocal of the initial reaction rate versus reciprocal of the acetylacetone concentration.

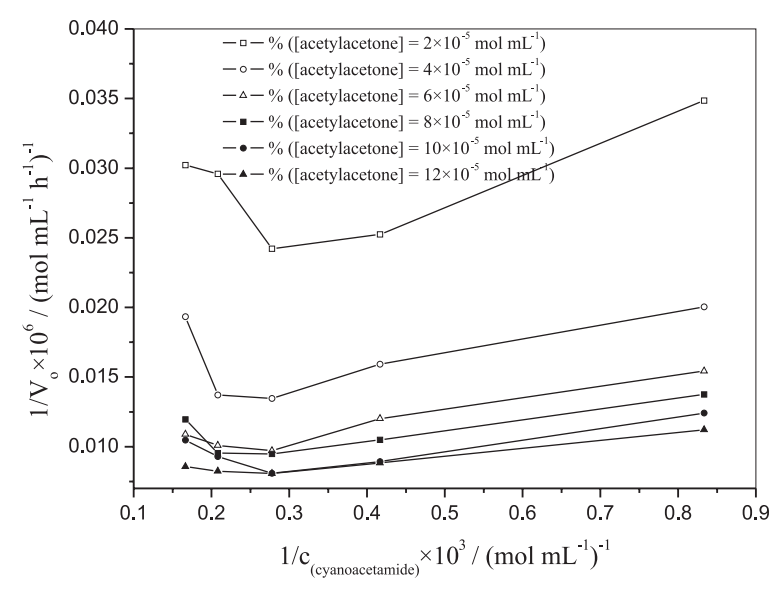

Figure 6. Reciprocal of the initial reaction rate versus reciprocal of the cyanoacetamide concentration.

The values of the parameters in equation 3 were calculated by multiple regression fitting of the experimental data. The results are given in Table 3.

Thus, the results of the kinetic studies suggest that the lipase-catalyzed synthesis of 4,6-dimethyl-3-cyano2-pyridone proceeds by the ping-pong bi-ter mechanism, which indicates that binding of the first substrate to the enzyme is followed by the release of the first product. Hence, it appears that the mechanism of the lipase-catalyzed synthesis of substituted 3-cyano-2-pyridones differs from the mechanism of the base-catalyzed reaction (Scheme 1). Based on previous studies, ${ }^{23}$ some further insight into the reaction mechanism can be made. Investigation of the influence of the structures of 3-alkyl-2,4-pentandione and $\mathrm{N}$-alkyl 
Table 3. The kinetic parameters for the synthesis of 4,6-dimethyl-3cyano-2-pyridone

\begin{tabular}{|c|c|}
\hline Parameter & Value \\
\hline$V_{\max }$ & $779( \pm 9.82) \mu \mathrm{mol} \mathrm{mL} L^{-1} \mathrm{~h}^{-1}$ \\
\hline$K_{\mathrm{m}, \mathrm{A}}$ & $2.02 \cdot 10^{-5}\left( \pm 0.91 \cdot 10^{-6}\right) \mathrm{mol} \mathrm{mL}^{-1}$ \\
\hline$K_{\mathrm{m}, \mathrm{B}}$ & $10.6 \cdot 10^{-3}\left( \pm 3.34 \cdot 10^{-4}\right) \mathrm{mol} \mathrm{mL}^{-1}$ \\
\hline$K_{\mathrm{i}, \mathrm{B}}$ & $0.280 \cdot 10^{-3}\left( \pm 1.22 \cdot 10^{-4}\right) \mathrm{mol} \mathrm{mL}^{-1}$ \\
\hline
\end{tabular}

cyanoacetamide on the yields and the rates of the synthesis of substituted 3-cyano-2-pyridones showed that increasing the bulkiness of the $\mathrm{N}$-alkyl substituent caused very small changes in the initial reaction rates; hence, the deprotonation of cyanoacetamide must be fast. On the other hand, the initial reaction rates dramatically fell with increasing bulkiness of the 3-alkyl group; hence, it is plausible that the binding of the diketone is the slow step of the reaction. Additionally, for elucidation of the mechanism, important catalytic properties of lipases must be taken into account. Since lipase from C. rugosa is a serine hydrolase, ${ }^{32,33}$ the first substrate reacts with the hydroxyl group of serine in active site and forms an enzyme-substrate complex. ${ }^{27}$ The second substrate then reacts with the formed complex in the deacetylation step to release the product(s) and free enzyme. Taking into account all the above-mentioned, it seems that the lipase-catalyzed syntheses of substituted 3-cyano-2-pyridones proceed according to mechanism presented in Figure 7 and Scheme 2.

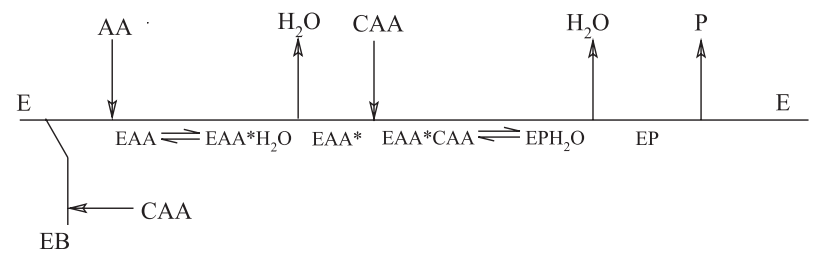

Figure 7. Schematic representation of the ping-pong bi-ter mechanism: E: enzyme (lipase), CAA: cyanoacetamide, AA: acetylacetone; P: pyridone; EAA, EP and ECAA: complexes of lipase and AA, P and CAA, respectively; EAA*: 1-methyl-3-oxo-but-1-enyl-enzyme complex and EB: complex of enzyme and cyanoacetamide.

In the first step, the nucleophilic oxygen from serine reacts with one of the carbonyl carbon atoms of the diketone. The other members of the catalytic triad, histidine and aspartic acid, participate in the stabilization of this structure. The nitrogen from histidine accepts a proton from serine, while aspartic acid delocalizes the charge by the formation of hydrogen bonds with histidine. ${ }^{27,32}$ In the second step, the first product of the reaction (water) is formed and released from active site. Then, the nucleophilic $\alpha$-carbon from cyanoacetamide attacks the formed complex, which is facilitated by the removal of a proton to a histidine and after a fast equilibrium cyclization, the last two products, water and substituted 3-cyano-2-pyridones, are released. The inhibitory effect of cyanoacetamide can be explained by the hypothesis that the nucleophilic oxygen from serine may react with the carbonyl group of cyanoacetamide, yielding a non-active complex, and thus hindering the first catalytic step.
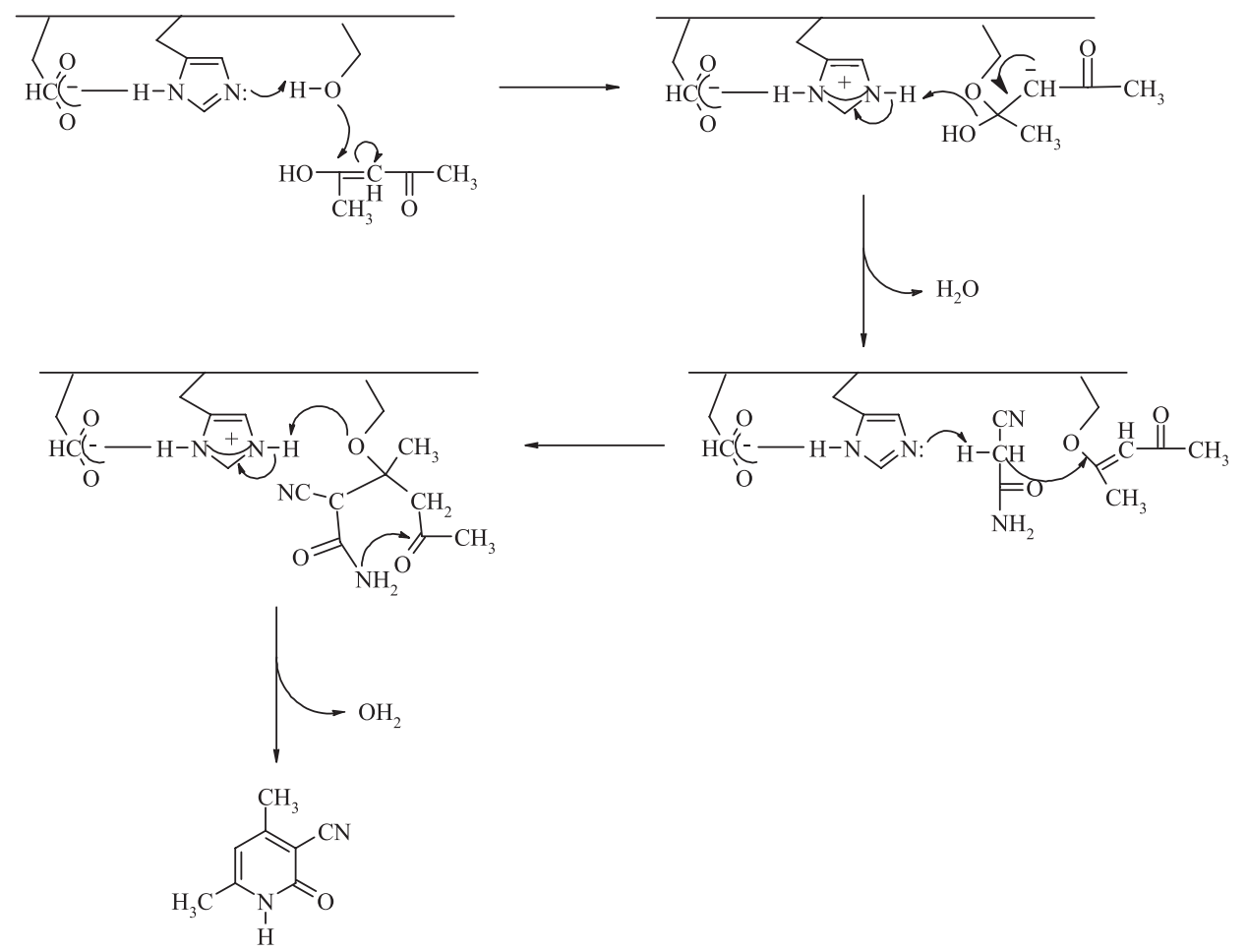

Scheme 2. Hypothetic mechanism of the enzyme catalyzed condensation reaction of cyanoacetamide and acetylacetone yielding 4,6-dimethyl-3-cyano-2-pyridone. 
The previously reported decrease of the initial rate with increasing bulkiness of 3-alkyl group, ${ }^{23}$ could be related to the shape of the active site of lipase from $C$. rugosa. It is generally recognized that lipase from $C$. rugosa has a tunnel-shaped active site, ${ }^{33,34}$ hence approach of bulkier substrates is feasible only with a favorable orientation. In a previous study, focused on the the specificity of lipase from C. rugosa in ester synthesis, ${ }^{35}$ it was found that the reaction was slower with acid substrates of similar bulkiness to those of diketones that exhibited low affinity in the synthesis of substituted 3-cyano-2-pyridones. ${ }^{23}$

\section{Conclusions}

The presented results clearly demonstrate that the catalytic activity of lipase from $C$. rugosa significantly increases the rate of 4,6-dimethyl-3-cyano-2-pyridone synthesis. The response surface methodology was employed to study the effects of the three factors important in the synthesis and proved itself to be a very useful method for the optimization of the experimental conditions. Statistical analysis showed that the temperature and molar ratio cyanoacetamide/acetylacetone have strong influences on the yield of the studied reaction. The kinetics of the reaction was analyzed under the optimal reaction conditions. The enzymatic synthesis of 4,6-dimethyl-3-cyano-2-pyridone can be described by the ping-pong bi-ter mechanism with cyanoacetamide inhibition. The obtained kinetic model was an important contribution towards the elucidation of the reaction mechanism. Both the determined optimal conditions, obtained using response surface methodology, and the obtained kinetic model will help in increasing the yields of substituted 3-cyano-2-pyridones synthesized in a lipase-catalyzed reaction and represent a good foundation for the development of enzymatic, environmentally friendly, processes for the synthesis of valuable chemicals having a very similar structure.

\section{Acknowledgments}

The authors acknowledge the financial support of the Ministry of Science and Technological Development of the Republic of Serbia (projects 142063 and TR-20064).

\section{References}

1. Mišić-Vuković, M.; Mijin, D.; Radojković-Veličković, M.; Valentić, N.; Krstić, V.; J. Serb. Chem. Soc. 1998, 63, 585.

2. Singh, B.; Lesher, G. Y.; US pat. 4,451,469 1984. (CA 101:P97662g)

3. Younadale, G. A.; US pat. 4,220,648 1980. (CA 95:P150456d)
4. Younadale, G. A.; Oglia, T. F.; J. Med. Chem. 1985, 28, 1790 .

5. Mijin, D.; Marinković, A.; Synth. Commun. 2006, 36, 193.

6. Liria, C. W.; Romagna, C. D.; Rodovalho, N. N.; Marana, S. R.; Miranda, M. T. M.; J. Braz. Chem. Soc. 2008, 19, 1574.

7. Maria, P. D.; Alvaro, E. F.; Kate, A. T.; Bargeman, G. J.; J. Mol. Catal. B: Enzym. 2009, 59, 220.

8. Hilal, N.; Kochkodan, V.; Nigmatullin, R.; Goncharuk, V.; AlKhatib, L.; J. Membr. Sci. 2006, 268, 198.

9. Carvalho, P. O.; Campos, P. R. B.; D’Addio Noffs, M.; Fregolente, P. B. L.; Fregolente, L. V.; J. Braz. Chem. Soc. 2009, $20,117$.

10. Chen, Z. G.; Tan, R. X.; Huang, M.; Process Biochem. 2010, $45,415$.

11. Bavaro, T.; Ubiali, D.; Brocca, S.; Rocchietti, S.; Nieto, I.; Pregnolato, M.; Lotti, M.; Terreni, M.; Biocatal. Biotransform. 2010, 28, 108.

12. Wang, Y.; Li, Q.; Zhang, Z.; Ma, J.; Feng, Y.; J. Mol. Catal. B: Enzym. 2009, 56, 146.

13. Zanotto, S. P.; Romano, I. P.; Lisboa, L. U. S.; Duvoisin Jr., S.; Martins, M. K.; Lima, F. A.; Silva, S. F.; Albuquerque, P. M.; J. Braz. Chem. Soc. 2009, 20, 1046.

14. Villeneuve, P.; Biotechnol. Adv. 2007, 25, 515.

15. Chen, H.-C.; Liang, Y.-T.; Chen, J.-H.; Chang, C.; Shieh, C.-J.; Biocatal. Biotransform. 2009, 27, 296.

16. Ghanem, A.; Tetrahedron 2007, 63, 1721.

17. Gotor-Fernandez, V.; Brieva, R.; Gotor, V.; J. Mol. Catal. B: Enzym. 2006, 40, 111.

18. Da Silva, V. C. F.; Contesini, F. J.; Carvalho, P. O.; J. Braz. Chem. Soc. 2008, 19, 1468.

19. Al Dulayymi, J. R.; Baird, M. S.; Jones, K.; Tetrahedron 2004, $60,341$.

20. Mijin, D.; Antonović, D.; Mišić-Vuković, M.; Indian J. Chem., Sect. B: Org. Chem. Incl. Med. Chem. 1994, 33, 309.

21. Mijin, D.; Mišić-Vuković, M.; Indian J. Chem., Sect. B: Org. Chem. Incl. Med. Chem. 1995, 34, 348.

22. Mijin, D.; Mišić-Vuković, M.; Indian J. Chem., Sect. B: Org. Chem. Incl. Med. Chem. 1998, 37, 988.

23. Mijin, D.; Milić, B.; Mišić-Vuković, M.; Indian J. Chem., Sect. B: Org. Chem. Incl. Med. Chem. 2006, 45, 61.

24. Eremia, S. A. V.; Chevalier-Lucia, D.; Radu, G.L.; Marty, J. L.; Talanta 2008, 77, 858.

25. Sudarjanto, G.; Keller-Lehmann, B.; Keller, J.; J. Hazard. Mater. 2006, $138 B, 160$.

26. Janssen, A. E. M.; Sjursnes, B. J.; Vakurov, A. V.; Halling, P.; Enzyme Microb. Technol. 1999, 24, 463.

27. Muralidhar, R. V.; Chirumamilla, R. R.; Marchant, R.; Ramachandran, V. N.; Ward, O. P.; Nigam, P.; World J. Microbiol. Biotechnol. 2002, 18, 81.

28. Bisswanger, H.; Enzyme Kinetics: Principles and Methods, $2^{\text {nd }}$ ed., Wiley: Weinheim, 2008. 
29. Segel, H.; Enzyme Kinetics: Behavior and Analysis of Rapid Equilibrium and Steady-State Enzyme Systems, John Wiley and Sons: New York, 1975. .

30. Marangoni, A. G.; Enzyme Kinetics: A Modern Approach, Wiley-Interscience: New York, 2003.

31. Hazarika, S.; Goswami, P.; Dutta, N. N.; Hazarika, A. K.; Chem. Eng. J. (Amsterdam, Neth.) 2002, 85, 61.

32. Holmquist, M.; Chem. Phys. Lipids 1998, 93, 57.

33. Cygler, M.; Schrag, J. D.; Biochim. Biophys. Acta, Mol. Cell. Biol. Lipids 1999, 1441, 205.
34. Pleiss, J.; Fischer, M.; Schmid, R. D.; Chem. Phys. Lipids 1998, 93, 67.

35. Bezbradica, D.; Karalazić, I.; Ognjanović, N.; Mijin, D.; ŠilerMarinković, S.; Knežević, Z.; J. Serb. Chem. Soc. 2006, 71, 31.

Submitted: March 9, 2010

Published online: August 24, 2010 